\title{
Effectiveness of preoperative autologous blood donation for protection against allogeneic blood exposure in adult spinal deformity surgeries: a propensity-matched cohort analysis
}

\author{
Michael P. Kelly, MD, MS, ${ }^{1}$ Lukas P. Zebala, MD, ${ }^{1}$ Han Jo Kim, MD, ${ }^{2}$ Daniel M. Sciubba, MD, ${ }^{3}$ \\ Justin S. Smith, MD, PhD, ${ }^{4}$ Christopher I. Shaffrey, MD, ${ }^{4}$ Shay Bess, MD, ${ }^{5}$ Eric Klineberg, MD, ${ }^{6}$ \\ Gregory Mundis Jr., MD, ${ }^{7}$ Douglas Burton, MD, ${ }^{8}$ Robert Hart, MD, ${ }^{9}$ Alex Soroceanu, MD, ${ }^{10}$ \\ Frank Schwab, MD, ${ }^{11}$ Virginie Lafage, PhD, ${ }^{11}$ and the International Spine Study Group
}

\begin{abstract}
${ }^{1}$ Department of Orthopedic Surgery, Washington University School of Medicine, Saint Louis, Missouri; ${ }^{2}$ Department of Orthopedic Surgery, Hospital for Special Surgery, New York, New York; ${ }^{2}$ Department of Neurological Surgery, Johns Hopkins University, School of Medicine, Baltimore, Maryland; ${ }^{4}$ Department of Neurological Surgery, University of Virginia School of Medicine, Charlottesville, Virginia; ${ }^{5}$ Rocky Mountain Hospital for Children, Denver, Colorado; ${ }^{6}$ Department of Orthopedic Surgery, University of California, Davis, Sacramento; ${ }^{7}$ San Diego Center for Spinal Disorders, La Jolla, California; ${ }^{8}$ Department of Orthopedic Surgery, University of Kansas Medical Center, Kansas City, Kansas; ${ }^{9}$ Department of Orthopedic Surgery, Oregon Health \& Science University, Portland, Oregon; ${ }^{10}$ Department of Surgery, University of Calgary, School of Medicine, Calgary, Alberta, Canada; and ${ }^{11}$ Department of Orthopedic Surgery, New York University, School of Medicine, New York, New York.
\end{abstract}

OBJECTIVE The goal of this study was to examine the effectiveness of preoperative autologous blood donation (PABD) in adult spinal deformity (ASD) surgery.

METHODS Patients undergoing single-stay ASD reconstructions were identified in a multicenter database. Patients were divided into groups according to PABD (either PABD or NoPABD). Propensity weighting was used to create matched cohorts of PABD and NoPABD patients. Allogeneic (ALLO) exposure, autologous (AUTO) wastage (unused AUTO), and complication rates were compared between groups.

RESULTS Four hundred twenty-eight patients were identified as meeting eligibility criteria. Sixty patients were treated with PABD, of whom 50 were matched to 50 patients who were not treated with PABD (NoPABD). Nearly one-third of patients in the PABD group $(18 / 60,30 \%)$ did not receive any autologous transfusion and donated blood was wasted. In 6 of these cases (6/60,10\%), patients received ALLO blood transfusions without AUTO. In 9 cases $(9 / 60,15 \%)$, patients received ALLO and AUTO blood transfusions. Overall rates of transfusion of any type were similar between groups (PABD $70 \%$ [42/60], NoPABD 75\% [275/368], $p=0.438$ ). Major and minor in-hospital complications were similar between groups (Major PABD 10\% [6/60], NoPABD 12\% [43/368], $p=0.537$; Minor PABD 30\% [18/60], NoPABD 24\% [87/368], p $=0.499$ ). When controlling for potential confounders, PABD patients were more likely to receive some transfusion (OR $15.1,95 \% \mathrm{Cl}$ 2.1-106.7). No relationship between PABD and ALLO blood exposure was observed, however, refuting the concept that PABD is protective against ALLO blood exposure. In the matched cohorts, PABD patients were more likely to sustain a major perioperative cardiac complication (PABD $8 / 50[16 \%]$, NoPABD 1/50 [2\%], $p=0.046$ ). No differences in rates of infection or wound-healing complications were observed between cohorts.

CONCLUSIONS Preoperative autologous blood donation was associated with a higher probability of perioperative transfusions of any type in patients with ASD. No protective effect of PABD against ALLO blood exposure was observed, and no risk of perioperative infectious complications was observed in patients exposed to ALLO blood only. The benefit of PABD in patients with ASD remains undefined.

http://thejns.org/doi/abs/10.3171/2015.4.SPINE141329

KEY WORDS adult spinal deformity; transfusion; autologous blood; allogeneic blood; complications

ABBREVIATIONS AIS = adolescent idiopathic scoliosis; $\mathrm{ALLO}=$ allogeneic; $\mathrm{ASD}=$ adult spinal deformity; $\mathrm{AUTO}=$ autologous; $\mathrm{BMI}=$ body mass index; $\mathrm{CCl}=\mathrm{Charlson}$ Comorbidity Index; EBL = estimated blood loss; PABD = preoperative autologous blood donation; $\mathrm{PRBC}$ = packed red blood cells.

SUBMITTED December 29, 2014. ACCEPTED April 10, 2015.

INCLUDE WHEN CITING Published online September 25, 2015; DOI: 10.3171/2015.4.SPINE141329. 
$\mathrm{C}$ OMPLEX adult spinal deformity (ASD) surgeries are increasing in incidence, as the population ages and the revision burden grows. ${ }^{15,16}$ Reconstructive surgeries for ASD are associated with long operative times and high estimated blood losses (EBLs). Consequently, resuscitation of these patients frequently requires transfusions of autologous (AUTO) or allogeneic (ALLO) packed red blood cells (PRBCs) to maintain circulating hemoglobin levels, in an effort to minimize perioperative complications. ${ }^{18}$ In fact, spine surgery is one of the most common procedures associated with PRBC transfusion in the US..$^{21,28}$

Transfusion of ALLO PRBCs is not without risk. Beyond the low risk of exposure to disease, a systemic inflammatory response occurs in response to proteins carried with the PRBCs. ${ }^{20,24,25}$ The most extreme of these inflammatory responses are known as transfusion-related acute lung injury and transfusion-associated circulatory overload, which carry risks of morbidity and mortality. ${ }^{22}$ Less extreme, but also concerning, is the increased risk of perioperative complications, particularly infections, related to exposure to ALLO PRBCs. ${ }^{2,8,26}$ This relationship has been shown in retrospective studies of patients with total joint arthroplasty and lumbar arthrodesis. ${ }^{2,26}$

An alternative to transfusion of ALLO blood is preoperative autologous blood donation (PABD) for postoperative transfusion. This hopefully eliminates or minimizes exposure to ALLO blood products. ${ }^{11}$ This modality is imperfect, however, as it may create an iatrogenic anemia, increasing the chance of requiring a postoperative transfusion, coupled with a lower transfusion threshold because of a belief that AUTO blood should be used.11,12 Autologous blood frequently goes unused and is wasted. ${ }^{1}$ Finally, transfusion errors can occur and, despite PABD, patients are erroneously transfused with ALLO blood. Despite these negative features, PABD is still performed, due probably in part to physician and patient preferences to avoid ALLO blood exposure.,, 10

The purpose of this study was to examine the use of PABD in a large cohort of patients with ASD. We sought to investigate the following: 1) the protective effect of PABD against exposure to ALLO blood; 2) the rates of blood wastage (unused PABD); and 3) the impact of AUTO and ALLO blood exposure on perioperative complications.

\section{Methods}

Patients undergoing surgery for ASD in a single hospital stay were identified in a multicenter cohort of patients with ASD from 11 sites in the US. Patients undergoing staged surgeries (anterior and posterior) within the same hospital stay were included in the cohort analyzed. Patients undergoing staged surgeries during separate hospital stays were excluded from the cohort. All sites received institutional review board approval. Eligibility criteria for inclusion in this cohort were age $>18$ years, the presence of a spinal deformity with scoliosis $>20^{\circ}$, sagittal vertical axis $>5 \mathrm{~cm}$, pelvic tilt $>25^{\circ}$, and/or a thoracic kyphosis $\geq 60^{\circ}$. Patients were excluded if they had a concomitant diagnosis of neuromuscular disease, infection, or malignancy.

Preoperative demographic data collected included age at surgery, sex, body mass index (BMI; $\left.\mathrm{m} / \mathrm{kg}^{2}\right)$, Charlson
Comorbidity Index (CCI) score, nicotine use, and medical comorbidities. Comorbidities collected included those associated with perioperative complications, such as diabetes mellitus, and those associated with higher risks of perioperative blood transfusion, such as cardiovascular diagnoses. PABD was performed at the surgeon's discretion and the volume donated was recorded.

Surgical data collected included whether the surgery was a primary or revision procedure; operative time; EBL; whether surgery was anterior, posterior, or circumferential (anterior and posterior); and the number of levels fused. It was noted if surgery was circumferential, performed the same day, or staged. For circumferential procedures, total EBL and operative times were calculated. These total EBL and operative times were used in the statistical analysis, because the temporal relationship between transfusions and the staged procedures was not available in the database. Thus, we collected data for EBL and operative times for the entire reconstruction.

Perioperative transfusions were administered at the surgeon's discretion. Intraoperative and postoperative transfusions of PRBCs, both AUTO and ALLO, were recorded as milliliters of blood. In some cases, centers reported the number of units transfused, without blood volume. To account for this, the average value of blood per unit in the cohort was calculated and this value served as a surrogate volume for 1 unit of blood. Transfusion triggers were left to the discretion of the attending surgeon and were not standardized across the cohort. The database was queried for occurrence of complications occurring within the hospital stay and these were classified as major or minor, as well as according to body system.

Descriptive data were compared using the independent sample Student t-test for normally distributed data, Mann-Whitney U-test for non-normally distributed data, and chi-square test for categorical data. Because PABD was not a randomly allocated intervention, matched patient cohorts of PABD and no PABD (NoPABD) were created using propensity weights. Covariates selected were known or reasonable predictors of the need for a perioperative PRBC transfusion. These were age, presence of an osteotomy, number of levels fused, BMI, CCI score, nicotine use, cardiac comorbidities, and EBL. Logistic regression was used to predict PABD and calculate propensity scores. Patients who predonated blood were matched with those who did not, based upon the propensity score with a tolerance of 0.1 . A tolerance of 0 means a perfect match and a tolerance of 1 is a random match. Using backward entry (entry at $p=0.05$, removal at $p=0.1$ ), logistic regression was used to evaluate the association between PABD and receipt of any transfusion, as well as the association between PABD and exposure to ALLO blood.

All statistical analysis was performed using SPSS (version 22; IBM). Statistical significance was defined as $\mathrm{p}<$ 0.05 .

\section{Results}

Four hundred twenty-eight patients underwent singlestay ASD surgery and were eligible for inclusion. Sixty patients were managed with PABD. Demographic data 
TABLE 1. Demographic, operative, and perioperative data for PABD and NoPABD cohorts*

\begin{tabular}{|c|c|c|c|}
\hline Variable & NoPABD, $n=368$ & PABD, $n=60$ & p Value \\
\hline Age, yrs & $58.4 \pm 14.8$ & $48.1 \pm 17.3$ & $<0.001$ \\
\hline Sex & & & 0.188 \\
\hline Female & $273(79.4)$ & $52(86.7)$ & \\
\hline Male & $71(20.6)$ & $8(13.3)$ & \\
\hline Missing/NR & 24 & 0 & \\
\hline $\mathrm{BMI}, \mathrm{kg} / \mathrm{m}^{2}$ & $28.1 \pm 8.1$ & $25.1 \pm 6.1$ & 0.002 \\
\hline $\mathrm{CCl}$ score & $1.6 \pm 1.7$ & $0.7 \pm 1.1$ & $<0.001$ \\
\hline ASA score & $2.4 \pm 0.6$ & $1.8 \pm 0.7$ & $<0.001$ \\
\hline Nicotine use & & & 0.539 \\
\hline No & $304(90.7)$ & $44(88)$ & \\
\hline Yes & $31(9.3)$ & $6(12)$ & \\
\hline Missing/NR & 33 & 10 & \\
\hline Cardiac comorbidity & & & 0.006 \\
\hline No & $214(58.2)$ & $46(76.7)$ & \\
\hline Yes & $154(41.8)$ & $14(23.3)$ & \\
\hline Total levels fused & $9.8 \pm 4.0$ & $8.8 \pm 4.4$ & 0.068 \\
\hline Osteotomy performed & & & 0.660 \\
\hline No & $14(3.8)$ & $3(5.0)$ & \\
\hline Yes & $354(96.2)$ & $57(95.0)$ & \\
\hline \multicolumn{4}{|l|}{ Osteotomy typef } \\
\hline Posterior column & $2.8 \pm 3.3$ & $1.9 \pm 2.7$ & 0.013 \\
\hline 3-Column & $95(26)$ & $10(17)$ & 0.127 \\
\hline Total interbody fusions & $1.5 \pm 1.6$ & $1.5 \pm 1.8$ & 0.841 \\
\hline ALIF & 32 & 6 & 0.742 \\
\hline PLIF & 114 & 9 & 0.005 \\
\hline TLIF & 52 & 4 & 0.112 \\
\hline XLIF & 19 & 12 & $<0.001$ \\
\hline Transsacral & 3 & 9 & $<0.001$ \\
\hline Total operative time, min & $422.2 \pm 205.1$ & $373.4 \pm 163.2$ & 0.062 \\
\hline Total EBL, ml & $1923.2 \pm 1698.8$ & $2198.4 \pm 1453.6$ & 0.238 \\
\hline Donated blood, ml & NA & $636.8 \pm 270.4$ & \\
\hline Total AUTO blood transfused, ml§ & NA & $373.4 \pm 527.4$ & \\
\hline Total ALLO blood transfused, ml & $1045.9 \pm 1193.0$ & $166.2 \pm 364.5$ & $<0.001$ \\
\hline
\end{tabular}

ALIF = anterior lumbar interbody fusion; ASA = American Society of Anesthesiologists ; NA = not applicable; NR = not recorded; PLIF = posterior lumbar interbody fusion; TLIF = transforaminal lumbar interbody fusion; XLIF = extreme lateral interbody fusion.

* Unless otherwise specified, values are expressed as the mean \pm SD or the number of patients $(\%)$.

$\dagger$ Independent Student t-test for continuous variables except Total EBL (Mann-Whitney U); chi-square test for categorical variables. Values in bold are statistically significant.

$\ddagger$ Posterior column osteotomy reported as average levels per case. Three-column osteotomy includes pedicle subtraction, vertebral column resection, and corpectomy.

$\S$ Excluding intraoperative cell salvage.

are shown in Table 1. PABD patients were younger, had a lower BMI, and had fewer medical comorbidities. Surgical data regarding length and magnitude of surgery were similar, including total levels fused (NoPABD mean 9.8 $\pm 4.0 \mathrm{SD}, \mathrm{PABD}$ mean $8.8 \pm 4.4 \mathrm{SD}, \mathrm{p}=0.068)$. Osteotomies (posterior column/pedicle subtraction/vertebral column resection) were commonly performed and similar between groups. Rates of major and minor perioperative infectious, neurological, cardiopulmonary, renal, and wound-related complications were similar between groups (Table 2). Nearly one-third of PABD patients $(30 \%, 18 / 60)$ did not receive any AUTO blood transfusions, and donated blood was wasted. In 12 of these cases, the patient did not receive any transfusion at all, whereas in 6 cases
(10\%), AUTO blood was unused and the patient received ALLO blood transfusion. In $15 \%$ of cases (9/60), PABD patients were transfused with ALLO blood, in addition to the predonated AUTO blood. Although rates of any transfusion were similar (PABD 70\% [42/60], NoPABD $75 \%$ [275/368], $\mathrm{p}=0.438)$, NoPABD was associated with a higher risk of exposure to ALLO blood (OR 33.6, 95\% CI 11.3-99.8). Rates of perioperative major and minor complications were similar among groups (Major PABD 10\% [6/60], NoPABD 12\% [43/368], $\mathrm{p}=0.537$; Minor PABD $30 \%$ [18/60], NoPABD 24\% [87/368], $p=0.499$ ).

Logistic regression was used to calculate propensity weights for the probability of PABD being performed. Fifty PABD patients were matched using propensity weights 
TABLE 2. Comparison of perioperative complications between PABD and NoPABD patient cohorts*

\begin{tabular}{lccc}
\hline \multicolumn{1}{c}{ Category } & $\begin{array}{c}\text { NoPABD, } \\
n=368\end{array}$ & $\begin{array}{c}\text { PABD, } \\
n=60\end{array}$ & $\begin{array}{c}p \\
\text { Value }\end{array}$ \\
\hline Infection & & & 0.949 \\
None & $341(92.7)$ & $55(91.7)$ & \\
Minor & $14(3.8)$ & $3(5.0)$ & \\
Major & $13(3.5)$ & $2(3.3)$ & \\
\hline Neurological & & & 0.775 \\
None & $342(92.9)$ & $55(91.7)$ & \\
Minor & $19(5.2)$ & $3(5.0)$ & \\
Major & $7(1.9)$ & $2(3.3)$ & \\
\hline Cardiopulmonary & & & 0.549 \\
None & $311(84.5)$ & $48(80.0)$ & \\
Minor & $43(11.7)$ & $10(16.7)$ & \\
Major & $9(2.5)$ & $2(3.3)$ & \\
Major \& minor & $5(1.4)$ & $0(0)$ & \\
\hline Renal & & & 0.719 \\
None & $364(98.9)$ & $60(100)$ & \\
Minor & $3(0.8)$ & $0(0)$ & \\
Major & $1(0.3)$ & $0(0)$ & \\
\hline Wound-healing problems & & & \\
None & $364(98.9)$ & $59(98.3)$ & 0.535 \\
Minor & $2(0.5)$ & $1(1.7)$ & \\
Major & $2(0.5)$ & $0(0)$ & \\
\hline Val & & & \\
\hline
\end{tabular}

* Values are expressed as number of patients (\%).

to 50 patients who did not predonate blood (Table 3 ). Ten PABD patients went unmatched and were excluded from further analysis. Age, baseline BMI, baseline CCI score, cardiac comorbidities, number of levels fused, total operative time, and whether an osteotomy was performed were similar. Cell salvage was more common in the PABD group (PABD 87\% [52/60], NoPABD 54\% [27/50], p < 0.001). Antifibrinolytic use was similar between groups (PABD $50 \%$ [30/60], NoPABD 54\% [27/50], $p=0.309$ ), although the choice of antifibrinolytic was not similar, with aminocaproic acid used more frequently in NoPABD (20/50) and tranexamic acid used more frequently in PABD (20/30). Patients treated with PABD sustained higher EBL in the propensity-matched cohort (PABD $2311 \pm 1467$, NoPABD $1393 \pm 2445, \mathrm{p}<0.025)$. When controlling for EBL and cell salvage, regression analyses revealed an association between PABD patients and those receiving any transfusion (OR 15.1, 95\% CI 2.1-106.7), indicating that PABD was associated with more frequent transfusions. No relationship was observed between PABD and exposure to ALLO blood, again controlling for EBL and cell salvage. PABD patients were more likely to sustain a major perioperative cardiopulmonary complication (PABD 8/50 [16\%], NoPABD 1/50 [2\%], $\mathrm{p}=0.046)$. The most common cardiopulmonary complication was minor pleural effusion (PABD 7/50 [14\%], NoPABD 0, $\mathrm{p}=0.0187$ ). No differences in rates of infection or wound-healing complications were observed (Table 4).

\section{Discussion}

Adult spinal deformity surgeries are associated with large volumes of blood loss and, subsequently, often as- sociated with the need for perioperative PRBC transfusion. ${ }^{13,28}$ The use of PRBC transfusions is an effort to maintain systemic hemoglobin levels and avoid complication while balancing the risks associated with excessive ALLO PRBC exposure. ${ }^{18}$ Surgeons may attempt to avoid the use of ALLO PRBCs, because this is associated with a systemic inflammatory response and may be associated with perioperative infectious complications. ${ }^{24-26}$ One method to avoid ALLO blood exposure is PABD. The purpose of this study was to investigate the effectiveness of PABD in adults undergoing surgery for ASD. We sought to examine both the avoidance of ALLO blood exposure and rates of wasted AUTO blood. The effect of PABD on acute, perioperative complications was also examined.

Four hundred twenty-eight patients were identified in this observational, multicenter cohort, with 60 patients (14\%) undergoing PABD. Nearly one-third of patients $(30 \%, 18 / 60)$ did not receive any autologous transfusion and, subsequently, the donated blood was discarded and wasted. Twelve of these patients received no blood transfusion at all, and 6 patients received blood that was not their donated blood. Overall, 15 patients $(15 / 60,25 \%)$ were exposed to ALLO blood despite PABD. Thus, avoidance of ALLO blood could be considered marginally successful. Regression analyses supported the theory that PABD patients are more likely to receive transfusions (OR 15.1, 2.1-106.7). These findings may be the result of lowered transfusion thresholds for patients with AUTO blood available, because AUTO blood transfusions may be deemed a safer intervention. PABD did not predispose patients to requiring ALLO blood, as has been hypothesized because of iatrogenic anemia. PABD also did not completely protect against ALLO blood exposure, one of the primary goals of PABD. No differences in overall complications were observed. Major cardiopulmonary complications, most commonly pleural effusions, were more common in patients treated with PABD, however. The reason for this association is not readily apparent. Unlike recent reports, exposure to ALLO blood was not associated with acute infectious complications, surgical site or otherwise.

Brookfield et al. found that for short-segment lumbar fusion procedures, PABD did not decrease exposure to ALLO blood and concluded that PABD was unlikely to be an effective intervention in these shorter procedures. ${ }^{4} \mathrm{Con}-$ versely, Solves et al. found that PABD decreased exposure to ALLO blood in a cohort of long-segment (a mean of 10 levels) fusions for spinal deformities, while increasing the probability of some transfusion. ${ }^{23}$ Similar to our findings, $18 \%$ of patients were exposed to ALLO blood despite PABD, although the volume of ALLO PRBCs transfused was lower with PABD. Wasted PABD with ALLO blood exposure is not uncommon, with rates as high as $40 \%$, and it is probable that laboratory or ordering error plays some role. ${ }^{6}$ The fact that PABD may not prevent ALLO blood exposure in adult surgeries is not surprising, particularly in ASD, where mean EBL often approaches 2 liters. In fact, the protective effect of PABD is most pronounced in adolescent idiopathic scoliosis (AIS) surgeries and in shorter lumbar fusion procedures., ${ }^{4,13,17}$ As intraoperative blood management measures improve (e.g., use of antifibrinolytics and cell salvage), ALLO blood exposure is 
TABLE 3. Demographic, operative, and perioperative data for matched cohorts of PABD and NoPABD patients*

\begin{tabular}{|c|c|c|c|}
\hline Variable & $\operatorname{NoPABD}(n=50)$ & $\operatorname{PABD}(n=50)$ & $p$ Value $†$ \\
\hline Age, yrs & $44.4 \pm 17.1$ & $48.7 \pm 17.6$ & 0.215 \\
\hline Sex & & & 0.358 \\
\hline Female & $36(77)$ & $42(84)$ & \\
\hline Male & $11(23)$ & $8(16)$ & \\
\hline NR & 3 & 0 & \\
\hline $\mathrm{BMI}, \mathrm{kg} / \mathrm{m}^{2}$ & $25.7 \pm 6.1$ & $25.4 \pm 6.5$ & 0.834 \\
\hline $\mathrm{CCl}$ score & $0.74 \pm 1.2$ & $0.76 \pm 1.1$ & 0.931 \\
\hline ASA score & $2.0 \pm 0.5$ & $1.9 \pm 0.7$ & 0.196 \\
\hline Nicotine use & & & 0.766 \\
\hline No & $43(86)$ & $44(88)$ & \\
\hline Yes & $7(14)$ & $6(12)$ & \\
\hline Cardiac comorbidity & & & 0.334 \\
\hline No & $41(82)$ & $37(74)$ & \\
\hline Yes & $9(18)$ & $13(26)$ & \\
\hline Total levels fused & $7.8 \pm 4.6$ & $9.2 \pm 4.1$ & 0.115 \\
\hline Osteotomy performed & & & 0.307 \\
\hline No & $1(2)$ & $3(6)$ & \\
\hline Yes & $49(98)$ & 47 (94) & \\
\hline \multicolumn{4}{|l|}{ Osteotomy typeł } \\
\hline Posterior column & $1.9 \pm 3.0$ & $1.9 \pm 2.7$ & 0.869 \\
\hline 3-Column osteotomy & $3(6.0)$ & $10(20)$ & 0.084 \\
\hline Total Interbody Fusions & $1.1 \pm 1.5$ & $1.4 \pm 1.7$ & 0.320 \\
\hline ALIF & $11(22.0)$ & $5(10.0)$ & 0.102 \\
\hline PLIF & $2(4.0)$ & $6(12.0)$ & 0.140 \\
\hline TLIF & $7(14.0)$ & $8(16.0)$ & 0.779 \\
\hline XLIF & $7(14.0)$ & $3(6.0)$ & 0.182 \\
\hline Transsacral & $0(0)$ & $9(18.0)$ & 0.002 \\
\hline Total operative time, min & $364.7 \pm 200.4$ & $375.2 \pm 161.2$ & 0.773 \\
\hline Total EBL, ml & $1393.4 \pm 2445.0$ & $2311.6 \pm 1467.4$ & 0.025 \\
\hline Donated blood, ml & NA & $665.2 \pm 272.9$ & \\
\hline Total AUTO blood transfused, ml§ & NA & $386.6 \pm 549.6$ & \\
\hline Total ALLO blood transfused, ml & $326.5 \pm 1220.3$ & $177.5 \pm 382.4$ & 0.413 \\
\hline
\end{tabular}

* Unless otherwise specified, values are expressed as the mean \pm SD or the number of patients (\%).

$\dagger$ Independent Student t-test for continuous variables except Total EBL (Mann-Whitney U); chi-square test for categorical variables. Values in bold are statistically significant.

‡ Posterior column osteotomy reported as average levels per case. Three-column osteotomy includes pedicle subtraction, vertebral column resection, and corpectomy.

$\S$ Excluding intraoperative cell salvage.

becoming more infrequent in AIS and the same may soon be the case in degenerative lumbar procedures. ${ }^{3}$

Historically, ALLO blood transfusions have been avoided because of concern related to the transmission of communicable diseases. With newer blood screening techniques, this risk is minimized and should not serve as a barrier to ALLO blood transfusions. More recent work supports an association between the exposure to ALLO blood and perioperative infections. Woods et al. found the volume of ALLO blood transfused was associated with an increased risk of infection in lumbar spine surgeries, suggesting a dose-response effect from ALLO PRBC transfusion. ${ }^{26}$ This cohort consisted of lumbar procedures only, however. The immunomodulatory effects of ALLO blood exposure have been confirmed, and further study within the ASD population is needed. ${ }^{24,25}$

A methodical approach to PABD, with patients identi- fied by demographic data and anticipated EBL, is needed. Some patients are unlikely to require any transfusion, whereas others are likely to require more blood than could be donated preoperatively., ${ }^{7,13,19}$ It is possible that ASD surgeries with high EBL are unlikely to benefit from AUTO blood donation, and those cases should be identified in advance. ${ }^{5,13,29}$ More frequent transfusions in PABD patients is a common finding, with evidence suggesting that iatrogenic anemia is the cause, compounded by a lower threshold to give AUTO blood in the postoperative period. ${ }^{12} \mathrm{~A}$ large, administrative database study showed PABD to be a risk factor for (i.e., not protective against) exposure to ALLO blood. ${ }^{27}$ Unfortunately, as with many retrospective studies similar to the present study, the reasons for transfusion were not recorded. In some cases, PABD may have been performed per a particular surgeon's routine; in others, PABD may have been performed in anticipation of a 
TABLE 4. Comparison of perioperative complications between matched cohorts of PABD and NoPABD patients*

\begin{tabular}{|c|c|c|c|}
\hline Category & $\begin{array}{c}\text { NoPABD } \\
n=50\end{array}$ & $\begin{array}{l}\text { PABD, } \\
n=50\end{array}$ & $\begin{array}{c}p \\
\text { Value }\end{array}$ \\
\hline Infection & & & 0.766 \\
\hline None & $46(92.0)$ & $46(92.0)$ & \\
\hline Minor & $1(2.0)^{\prime}$ & $2(4.0)^{\prime}$ & \\
\hline Major & $3(6.0)$ & $2(4.0)$ & \\
\hline Neurological & & & 0.489 \\
\hline None & $48(96.0)$ & $45(90.0)$ & \\
\hline Minor & $1(2.0)$ & $2(4.0)$ & \\
\hline Major & $1(2.0)$ & $3(6.0)$ & \\
\hline Cardiopulmonary & & & 0.106 \\
\hline None & $47(94.0)$ & $40(80.0)$ & \\
\hline Minor & $2(4.0)$ & $2(4.0)$ & \\
\hline Major & $1(2.0)$ & $8(16.0)$ & $0.046 \dagger$ \\
\hline Renal & & & NA \\
\hline None & $50(100)$ & $50(100)$ & \\
\hline Wound-healing problems & & & NA \\
\hline None & $50(100)$ & $50(100)$ & \\
\hline
\end{tabular}

* All values are expressed as number of patients (\%).

$\dagger$ Statistically significant.

case involving high blood loss. It seems that PABD is not effective in low and high EBL cases. The true utility of PABD in ASD, if it exists, remains to be shown.

This study is not without limitations. The situation surrounding the decision to perform PABD is not known. Some surgeons may perform PABD routinely, whereas others may use it only when they believe blood requirements will be high. To address this limitation, we created matched cohorts based upon patient factors that may have influenced the decision to perform PABD. The reasons for transfusion of AUTO and ALLO blood are not known. There is no standardized perioperative transfusion protocol in this study group, and what triggers transfusion at one institution may not be observed at another. We used regression techniques, controlling for known and reasonable confounding variables, in an attempt to address this limitation. We do not know why 18 patients did not receive predonated blood. In some cases, when no blood was transfused, the patient may not have manifested symptoms of anemia. In cases where ALLO blood was transfused without AUTO, laboratory or ordering error may have been at fault, emphasizing the inefficiencies associated with PABD..$^{14}$ The temporal relationship of any complication and blood transfusion is not known. For the purposes of patient counseling and preoperative decision making, this is less important, as PABD was associated with the complication without implying causality. Finally, our study was underpowered to detect differences in rare occurrences, such as transmission of communicable disease via ALLO blood transfusion or transfusion-associated acute lung injury (TRALI)/transfusion-associated circulatory overload (TACO) related to ALLO, although the rare nature of these events will make them difficult to study in any cohort. A similarly sized study did find a relationship between perioperative transfusions and infection, suggesting that our study was adequately powered for this outcome. ${ }^{20}$

\section{Conclusions}

This study supports the concept that PABD may not be effective in ASD, as $25 \%$ of patients were exposed to ALLO blood, 30\% of cases received no transfusion, and, in a propensity-matched cohort, PABD did not protect against ALLO blood exposure. This is probably due to the large EBL associated with these procedures and the inability of patients to donate a quantity sufficient to protect against transfusions of ALLO blood. Similar to previous work, PABD was imperfect and, not infrequently, donated blood was not given and thus wasted. No differences in perioperative infectious or wound-healing complications existed, as has been previously proposed ${ }^{26}$ As may be expected, patients receiving any transfusion were at higher risk for perioperative cardiopulmonary complications. Further retrospective studies will probably agree with the literature, which is mixed with respect to results, due in part to recall and performance biases. Studies to date thus offer little evidence to support clinical decision making and patient counseling. The cost-effectiveness of PABD has been questioned, and future studies should include economic data. ${ }^{9}$ Prospective studies to determine the clinical and cost-effectiveness of PABD in ASD are required, with attention to PABD timing, reasons for transfusion, and volume of ALLO PRBCs transfused.

\section{References}

1. Bess RS, Lenke LG, Bridwell KH, Steger-May K, Hensley M: Wasting of preoperatively donated autologous blood in the surgical treatment of adolescent idiopathic scoliosis. Spine (Phila Pa 1976) 31:2375-2380, 2006

2. Bierbaum BE, Callaghan JJ, Galante JO, Rubash HE, Tooms RE, Welch RB: An analysis of blood management in patients having a total hip or knee arthroplasty. J Bone Joint Surg Am 81:2-10, 1999

3. Bowen RE, Gardner S, Scaduto AA, Eagan M, Beckstead J: Efficacy of intraoperative cell salvage systems in pediatric idiopathic scoliosis patients undergoing posterior spinal fusion with segmental spinal instrumentation. Spine (Phila Pa 1976) 35:246-251, 2010

4. Brookfield KF, Brown MD, Henriques SM, Buttacavoli FA, Seitz AP: Allogeneic transfusion after predonation of blood for elective spine surgery. Clin Orthop Relat Res 466:19491953, 2008

5. Carabini LM, Zeeni C, Moreland NC, Gould RW, Avram MJ, Hemmer LB, et al: Development and validation of a generalizable model for predicting major transfusion during spine fusion surgery. J Neurosurg Anesthesiol 26:205-215, 2014

6. Cha CW, Deible C, Muzzonigro T, Lopez-Plaza I, Vogt M, Kang JD: Allogeneic transfusion requirements after autologous donations in posterior lumbar surgeries. Spine (Phila Pa 1976) 27:99-104, 2002

7. Couvret C, Tricoche S, Baud A, Dabo B, Buchet S, Palud M, et al: The reduction of preoperative autologous blood donation for primary total hip or knee arthroplasty: the effect on subsequent transfusion rates. Anesth Analg 94:815-823, 2002

8. Davies L, Brown TJ, Haynes S, Payne K, Elliott RA, McCollum C: Cost-effectiveness of cell salvage and alternative methods of minimising perioperative allogeneic blood transfusion: a systematic review and economic model. Health Technol Assess 10:iii-iv, ix-x, 1-210, 2006

9. Etchason J, Petz L, Keeler E, Calhoun L, Kleinman S, Snider $\mathrm{C}$, et al: The cost effectiveness of preoperative autologous blood donations. N Engl J Med 332:719-724, 1995 
10. Goldman M, Savard R, Long A, Gélinas S, Germain M: Declining value of preoperative autologous donation. Transfusion 42:819-823, 2002

11. Graham ID, Fergusson D, Dokainish H, Biggs J, McAuley L, Laupacis A: Autologous versus allogeneic transfusion: patients' perceptions and experiences. CMAJ 160:989-995, 1999

12. Kennedy C, Leonard M, Devitt A, Girardi FP, Cammisa FP Jr: Efficacy of preoperative autologous blood donation for elective posterior lumbar spinal surgery. Spine (Phila Pa 1976) 36:E1736-E1743, 2011

13. Lenoir B, Merckx P, Paugam-Burtz C, Dauzac C, Agostini MM, Guigui $P$, et al: Individual probability of allogeneic erythrocyte transfusion in elective spine surgery: the predictive model of transfusion in spine surgery. Anesthesiology 110:1050-1060, 2009

14. Linden JV: Errors in transfusion medicine. Scope of the problem. Arch Pathol Lab Med 123:563-565, 1999

15. Martin BI, Mirza SK, Comstock BA, Gray DT, Kreuter W, Deyo RA: Are lumbar spine reoperation rates falling with greater use of fusion surgery and new surgical technology? Spine (Phila Pa 1976) 32:2119-2126, 2007

16. Martin BI, Mirza SK, Comstock BA, Gray DT, Kreuter W, Deyo RA: Reoperation rates following lumbar spine surgery and the influence of spinal fusion procedures. Spine (Phila Pa 1976) 32:382-387, 2007

17. Murray DJ, Forbes RB, Titone MB, Weinstein SL: Transfusion management in pediatric and adolescent scoliosis surgery. Efficacy of autologous blood. Spine (Phila Pa 1976) 22:2735-2740, 1997

18. Pull ter Gunne AF, Skolasky RL, Ross H, van Laarhoven CJ, Cohen DB: Influence of perioperative resuscitation status on postoperative spine surgery complications. Spine (Phila Pa 1976) J 10:129-135, 2010

19. Reitman CA, Watters WC III, Sassard WR: The Cell Saver in adult lumbar fusion surgery: a cost-benefit outcomes study. Spine (Phila Pa 1976) 29:1580-1584, 2004

20. Schwarzkopf R, Chung C, Park JJ, Walsh M, Spivak JM, Steiger D: Effects of perioperative blood product use on surgical site infection following thoracic and lumbar spinal surgery. Spine (Phila Pa 1976) 35:340-346, 2010

21. Segal JB, Guallar E, Powe NR: Autologous blood transfusion in the United States: clinical and nonclinical determinants of use. Transfusion 41:1539-1547, 2001

22. Skeate RC, Eastlund T: Distinguishing between transfusion related acute lung injury and transfusion associated circulatory overload. Curr Opin Hematol 14:682-687, 2007

23. Solves P, Carpio N, Moscardo F, Bas T, Cañigral C, Salazar $\mathrm{C}$, et al: Results of a preoperative autologous blood donation program for patients undergoing elective major spine surgery. Transfus Apheresis Sci 49:345-348, 2013

24. Talbot TR, D'Agata EM, Brinsko V, Lee B, Speroff T, Schaffner W: Perioperative blood transfusion is predictive of poststernotomy surgical site infection: marker for morbidity or true immunosuppressant? Clin Infect Dis 38:1378-1382, 2004

25. Vamvakas EC, Carven JH: Transfusion of white-cell containing allogeneic blood components and postoperative wound infection: effect of confounding factors. Transfus Med 8:29-36, 1998

26. Woods BI, Rosario BL, Chen A, Waters JH, Donaldson W III, Kang J, et al: The association between perioperative allogeneic transfusion volume and postoperative infection in patients following lumbar spine surgery. J Bone Joint Surg Am 95:2105-2110, 2013

27. Yoshihara H, Yoneoka D: Predictors of allogeneic blood transfusion in total hip and knee arthroplasty in the United States, 2000-2009. J Arthroplasty 29:1736-1740, 2014

28. Yoshihara H, Yoneoka D: Trends in the utilization of blood transfusions in spinal fusion in the United States from 2000 to 2009. Spine (Phila Pa 1976) 39:297-303, 2014
29. Zheng F, Cammisa FP Jr, Sandhu HS, Girardi FP, Khan SN: Factors predicting hospital stay, operative time, blood loss, and transfusion in patients undergoing revision posterior lumbar spine decompression, fusion, and segmental instrumentation. Spine (Phila Pa 1976) 27:818-824, 2002

\section{Disclosure}

Research reported in this publication was supported by the Washington University Institute of Clinical and Translational Sciences grant UL1 TR000448 from the National Center for Advancing Translational Sciences (NCATS) of the National Institutes of Health (NIH). The content is solely the responsibility of the authors and does not necessarily represent the official view of the $\mathrm{NIH}$. Research reported in this publication also received research support from DePuy Synthes Spine grant funds. Dr. Shaffrey is a patent holder for Medtronic, Biomet, and NuVasive. He is a consultant for Biomet, Medtronic, NuVasive, and Stryker. He has direct stock ownership in NuVasive. Dr. Smith is a consultant for Biomet. He has received clinical or research support for this study (includes equipment or material) from DePuy Synthes. He is a consultant for NuVasive, Cerapedics, and Medtronic. He receives royalties from Biomet and research support from DePuy Synthes. Dr. Sciubba is a consultant for DePuy Synthes, Medtronic, NuVasive, and Stryker. Dr. Hart is a consultant for DePuy Synthes, Globus, and Medtronic. He is a patent holder for OHSU and receives royalties from both Seaspine and DePuy Synthes. He is on the speaker bureau of and receives paid honoraria from DePuy Synthes. He is a board member for CSRS, ISSLS, and ISSG. Dr. Lafage has direct stock ownership in Nemaris. She receives research support from DePuy, SRS, ISSG, and NIH. She is a speaker/ teacher for DePuy, K2M, NuVasive, Medicrea, and Nemaris. Dr. Schwab has direct stock ownership in Nemaris. He is a consultant for MSD, K2M, Biomet, and Medicrea. He receives research support from DePuy, MSD, and AOSpine. He is a patent holder for MSD and K2M. He is a speaker/teacher for MSD, Nemaris, Medicrea, and K2M. Dr. Burton is a consultant for DePuy Spine. He has received clinical or research support for this study (includes equipment or material) from DePuy Spine. He is a patent holder for DePuy Spine. Dr. Bess is a consultant for K2M and Allosource. He has received clinical or research support for this study (includes equipment or material) from DePuy Synthes Spine. He also receives research support from Innovasis, Medtronic, and K2M. Dr. Mundis is a consultant for NuVasive, K2M, Misonix, and Medicrea. He receives royalties from NuVasive and K2M. Dr. Klineberg receives honoraria from DePuy Synthes, grants from AOSpine, and a fellowship grant from OREF. Dr. Zebala is a consultant for Ulrich. Dr. Kelly receives research support from OREF, AOSpine, Barnes Jewish Foundation, and the Cervical Spine Research Society. Dr. Kim is a consultant for Medtronic, Biomet, and K2M. He has received clinical or research support for this study (includes equipment or material) from DePuy and also receives research support from Biomet.

\section{Author Contributions}

Conception and design: Kelly, Zebala, Smith, Bess, Soroceanu, Lafage. Acquisition of data: Sciubba, Smith, Shaffrey, Bess, Klineberg, Mundis, Burton, Hart, Schwab, Lafage. Analysis and interpretation of data: Kelly, Kim. Drafting the article: Kelly, Sciubba. Critically revising the article: Zebala, Kim, Sciubba, Smith, Bess, Mundis. Reviewed submitted version of manuscript: all authors. Approved the final version of the manuscript on behalf of all authors: Kelly. Statistical analysis: Kelly, Kim, Soroceanu.

\section{Correspondence}

Michael P. Kelly, Department of Orthopedic Surgery, Washington University School of Medicine, 660 S. Euclid Ave., Box 8233, Saint Louis, MO 63110. email: kellymi@wudosis.wustl.edu. 